\title{
PEMBUATAN DAN KARAKTERISASI MEMBRAN REAKTOR ZEOLIT
}

\section{MAKING AND CHARACTERIZATION OF ZEOLITE MEMBRANE REACTOR}

\author{
Hens Saputra, Endro Wahju Tjahjono \\ Pusat Pengkajian dan Penerapan Teknologi Industri Proses BPPT \\ Gedung Teknologi 2 Lantai 3 PUSPIPTEK Serpong \\ Tangerang Selatan 15314 \\ Telp.(021)75875944 ext 133; Fax.(021)75791280; \\ e-mail: henssaputra@yahoo.com \\ enwacah@yahoo.com
}

\begin{abstract}
Abstrak
Membran reaktor merupakan konsep perpaduan dari sistem reaksi dan proses pemisahan/pemurnian. Membran ini disebut juga sebagai membran katalis atau sistem katalis-membran. Dengan membran reaktor ini diharapkan konversi suatu reaksi dapat ditingkatkan dan diperoleh suatu produk yang memiliki tingkat kemurnian lebih tinggi. Sebagai katalis digunakan silica alumina yang berukuran 1,0 mm. Membran anorganik zeolit MFI dilapiskan menutupi seluruh permukaan katalis. Bahan baku yang digunakan antara lain tetraethylortosilikat (TEOS) sebagai sumber silikat dan template organik tetraprophyl ammonium bromide (TPABr). Proses kristalisasi dilakukan pada temperatur $453 \mathrm{~K}$ di dalam autogeneous autoclave, dilanjutkan dengan kalsinasi pada temperatur $873 \mathrm{~K}$ selama 1 jam. Karakterisasi membran zeolit yang dihasilkan dilakukan dengan X-ray diffraction (XRD) dan pengamatan dengan Scanning Electron Mycroscope (SEM). Karakteristik pori dipelajari menggunakan metode physisorption dan BJH pore size distribution. Selain itu dilakukan pula uji selektifitas dan alkilasi toluena dan xylene. Berdasarkan pengamatan menggunakan XRD mengindikasikan adanya struktur zeolit MFI pada sampel membrane katalis yang dihasilkan. Diperkuat dengan obserbasi SEM menunjukkan bahwa membran zeolit MFI melapisi seluruh permukaan pelet silika alumina dan terdapat indikasi terjadinya komposit terhadap silika alumina pada daerah perbatasan antara membran zeolit atau lapisan bagian luar dengan katalis silika alumina. Hasil pengujian menunjukkan hasil bahwa membran reaktor zeolit MFI berpotensi untuk diaplikasikan sebagai membran katalis yang bersifat sangat selektif terhadap bentuk suatu molekul. Sebagai contoh kasus, suatu isomer dapat dipisahkan satu sama lain secara selektif, sehingga dapat meningkatkan konversi reaksi.
\end{abstract}

Kata kunci : Membran reaktor, isomer, xylene, zeolit, silika alumina, hydrothermal.

\begin{abstract}
Membrane fusion reactor is the concept of the reaction system and the process of separation/purification. These membranes are called also as membrane catalysts or catalyst - membrane system . With the membrane reactor is expected conversion reaction can be improved and obtained a product which has a higher degree of purity. As used silica alumina catalyst measuring $1.0 \mathrm{~mm}$. MFI zeolite coated inorganic membranes covering the entire surface of the catalyst. The raw materials used include tetraethylortosilikat (TEOS) as a source of silicate and organic template tetraprophyl ammonium bromide ( $\mathrm{TPABr}$ ) . Crystallization process carried out at a temperature of $453 \mathrm{~K}$ in the autogeneous autoclave , followed by calcination at a temperature of $873 \mathrm{~K}$ for 1 hour. Characterization of zeolite membranes produced by $X$ - ray done diffraction ( XRD ) and scanning
\end{abstract}


electron observations with Mycroscope ( SEM). Pore characteristics studied physisorption using BJH pore size and distribution. Test will be conducted and the selectivity of toluene and xylene alkylation. Based on observations using XRD indicates the MFI zeolite structure on the resulting catalyst membrane samples. Reinforced with obserbasi SEM showed that the MFI zeolite membrane coating the entire surface of the silica- alumina pellets and there are indications of the silicaalumina composite in the border area between the zeolite membrane or outer layer of silica alumina catalyst. The results show that the results of the MFI zeolite membrane reactor has the potential to be applied as the membrane is highly selective catalyst to form a molecule. As an example case, an isomer can be separated from each other selectively, so as to increase the reaction conversion

Keywords: Membrane reactors, isomers, xylene, zeolite, silica alumina, hydrothermal .

Diterima (received) : 31 Januari 2014, Direvisi (reviewed) : 8 Februari 2014,

Disetujui (accepted) : 27 Februari 2014

\section{PENDAHULUAN}

Membran reaktor atau disebut juga sebagai membran katalis atau sistem katalis-membran adalah merupakan gabungan dari sistem yang terdiri dari proses reaksi dan proses pemisahan/pemurnian menjadi satu sistem yang kompak ${ }^{1,2)}$. Dengan membran reaktor ini diharapkan dapat meningkatkan konversi suatu reaksi yang dikehendaki sekaligus meningkatkan derajat kemurnian produk yang dihasilkan dan efisiensi tempat karena adanya penggabungan dua unit proses menjadi satu. Membran berfungsi memisahkan bahan baku yang memiliki kemurnian rendah secara selektif untuk masuk kedalam system agar dapat lebih efektif dan efisien terjadinya reaksi dengan kehadiran katalis. Selain itu membran juga berperan memurnikan produk hasil reaksi yang keluar dari system agar memiliki derajat kemurnian yang tinggi ${ }^{1)}$.

Pada makalah ini membahas pembuatan membran reactor yang terdiri dari membran anorganik zeolit MFI dan katalis silika alumina. Karakterisasi produk menggunakan XRD, SEM dan Physisorption. Uji produksi p-xylene dilakukan dengan mereaksikan toluena dan

\section{Membran dan Konsep Membran Reaktor}

Berdasarkan bahan baku yang digunakan pada proses pembuatannya, membaran sintetis dapat diklasifikasikan menjadi dua yaitu membran organik dan membran anorganik $^{3)}$. Membran organik adalah membran yang terbuat dari bahan-bahan seperti polimer, komposit, dll. Sedangkan membran anorganik adalah membran yang terbuat dari bahan-bahan anorganik seperti keramik, logam, dll.

Membran organik sudah lebih dahulu dikembangkan dan diaplikasikan pada skala komersial karena lebih mudah disintesa dibandingkan dengan membran anorganik serta biaya pembuatannya lebih murah. Tetapi membran ini memiliki keterbatasan, antara lain tidak tahan terhadap temperatur yang tinggi serta pelarut organik atau bahan kimia yang bersifat ekstrim asam atau basa. Membran anorganik lebih sulit dibuat karena sifat fisiknya yang kaku dan keras tetapi memiliki stabilitas yang sangat baik terhadap temperatur tinggi, pelarut organik dan bahan kimia asam maupun basa. Dengan pertimbangan spesifikasinya tersebut, maka membran anorganik dipilih untuk dibuat menjadi membran reaktor.

Prinsip kerja membran adalah memisahkan suatu molekul atau bahan berdasarkan ukuran dan bentuknya ${ }^{4}$. Ukuran yang lebih besar tidak dapat masuk kedalam pori dan melewati membrane, sedangkan ukuran yang lebih kecil melewati membran sebagai permeate. Ukuran beberapa material dan membran serta contoh molekul dapat dilihat pada Gambar 1. 


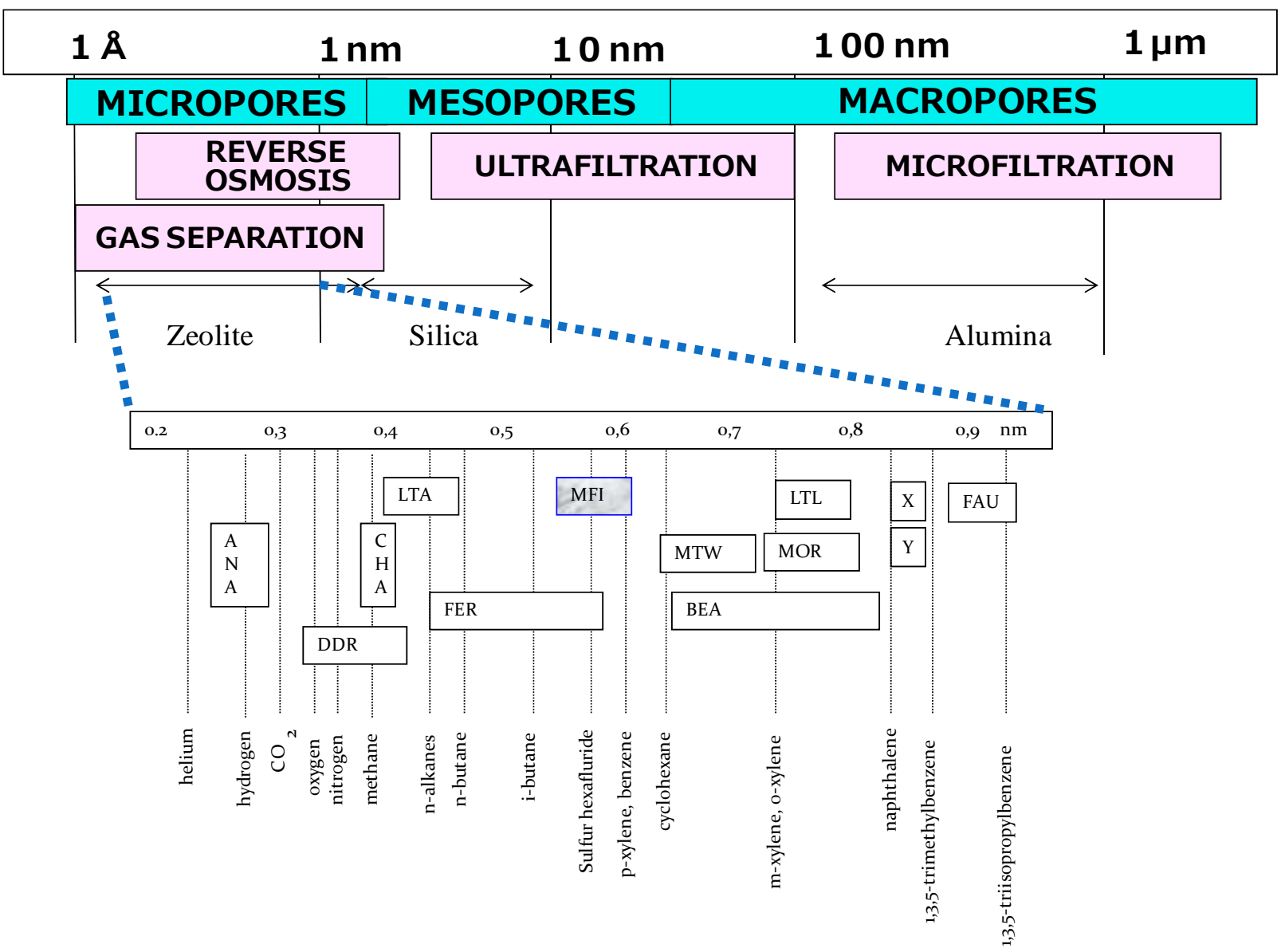

Gambar 1.

Klasifikasi membrane dan ukuran beberapa contoh molekul

Pemisahan menggunakan prinsip perbedaan bentuk terjadi pada contoh kasus pemisahan isomer $\mathrm{p}$-xylene terhadap o-xylene dan m-xylene. Ketiga isomer tersebut memilii berat dan ukuran molekul sama, tetapi bentuknya dibedakan dengan gugus alkyl yang menempel pada struktur aromatiknya. Sehingga hanya p-xylene yang dapat melewati membran, Gambar 2.

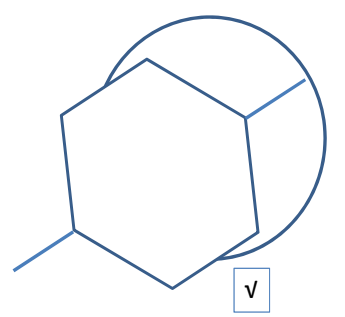

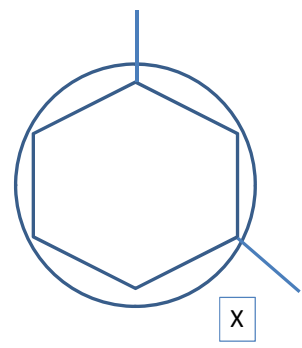

Gambar 2.

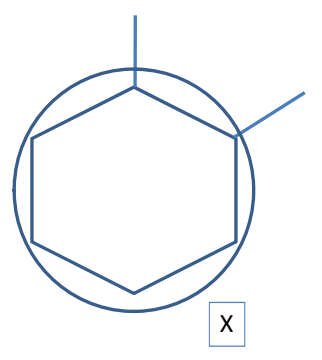

Ilustrasi pemisahan $\mathrm{p}$-xylene terhadap o- dan m-xylene menggunakan membran

Adapun prinsip kerja suatu membran reaktor adalah sebagaimana terlihat pada Gambar 3. Pada Gambar 3.a menjelaskan adanya selektifitas yang tinggi oleh membran terhadap reaktan. Dalam hal ini memungkinkan untuk terjadinya reaksi A menjadi $\mathrm{R}$ dan $\mathrm{B}$ menjadi S. Akan tetapi reaksi B menjadi S tidak dikehendaki atau dengan kata lain produk $\mathrm{R}$ lebih diharapkan daripada S. Maka membran yang melapisi seluruh permukaan katalis diharapkan dapat memisahkan secara selektif $A$ dan $B$, dimana reaktan $A$ dapat melewati membran menuju inti katalis sedangkan reaktan B tidak dapat melewati membran. Gambar 3.b menjelaskan adanya pemisahan produk secara selektif pada produk yang mengalami kesetimbangan dengan side product. Dengan demikian maka komponen $\mathrm{R}$ dapat ditingkatkan jumlahnya dalam produk ${ }^{5}$. 


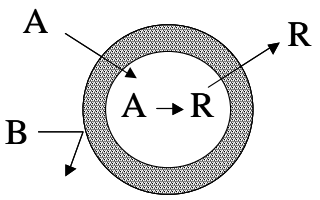

(a)

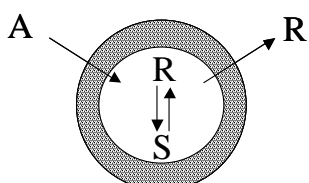

(b)
Gambar 3.

Prinsip operasi membran reactor

\section{METODE}

Proses pembuatan membran reaktor pada penelitian ini adalah menggunakan bahan silika alumina sebagai katalis dengan komposisi $82 \%$
$\mathrm{SiO}_{2}$ dan $13 \% \quad \mathrm{Al}_{2} \mathrm{O}_{3}$. Katalis silika alumina tersebut diseragamkan ukurannya menjadi sekitar $1 \mathrm{~mm}$. Proses pelapisan membran zeolit dibuat dari larutan induk yang terdiri dari colloidal silica, tetrapropylammonium bromide (TPABr), tetrapropylammonium hidroxide (TPAOH) dan aquades. Katalis silika alumina dimasukkan dalam larutan induk tersebut. Proses kristalisasi zeolit dilakukan pada temperatur $453 \mathrm{~K}$ selama 24 jam. Selanjutnya dicuci menggunakan aquades, dikeringkan dan dikalsinasi pada temperatur $873 \mathrm{~K}$ selama 1 jam. Secara lengkap tahapan proses pembuatan membran reaktor ini seperti pada Gambar 4.

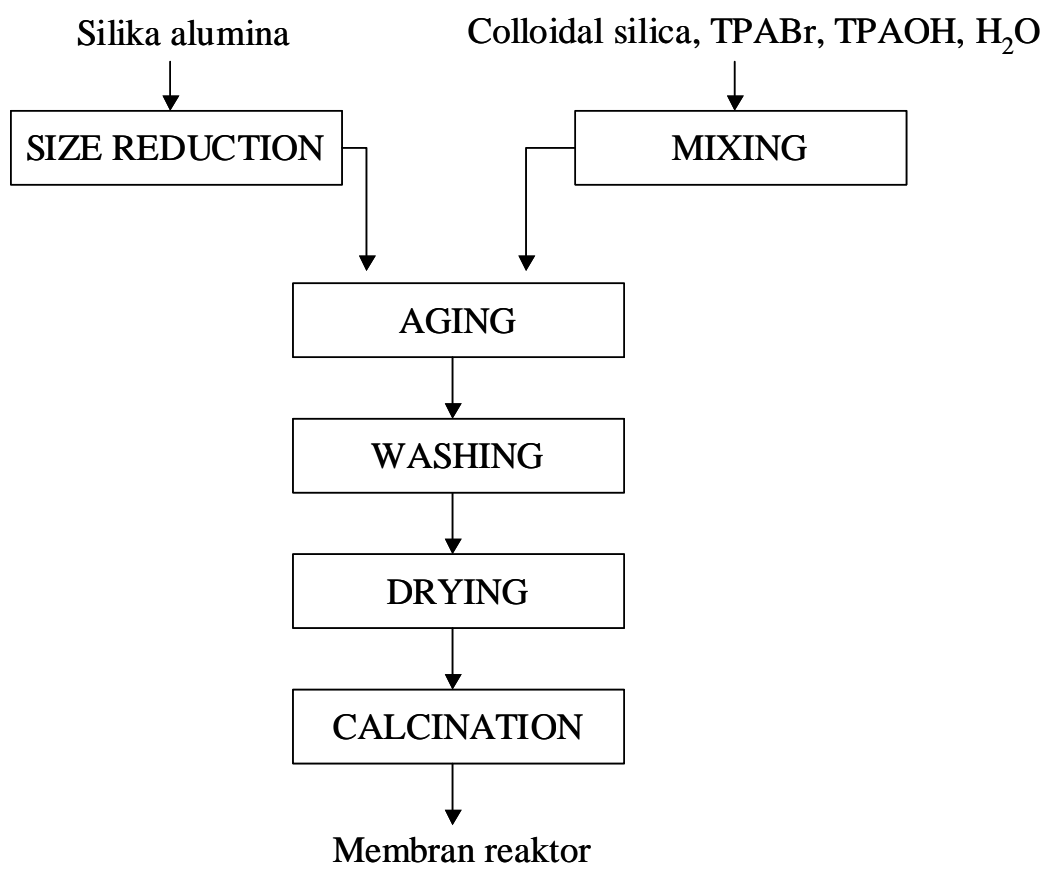

Gambar 4.

Diagram proses pembuatan membran reaktor zeolit MFI-silika alumina

Karakterisasi produk membran reaktor yang dihasilkan dilakukan menggunakan $X$-ray diffraction (XRD) untuk mengidentifikasi struktur zeolit pada lapisan permukaan silika alumina, diperkuat oleh data pengamatan menggunakan Scanning Electron Mycroscope (SEM) dan ujicoba proses pembentukan xylene dari toluene, yang dikontrol menggunakan gas kromatografi yang dipasang secara on line. Karakteristik pori membran dianalisis dengan metode adsorpsi-desorpsi isothermal menggunakan nitrogen pada $44 \mathrm{~K}$. Tekanan uap relatif ditingkatkan dari 0 hingga 1 dengan kenaikan/increment 0,001. Data yang diperoleh dari Autosorb 1, Quantachrome dapat menghasilkan distribusi ukuran pori BJH.

\section{HASIL DAN PEMBAHASAN}

Berdasarkan hasil analisis menggunakan XRD diketahui bahwa telah dihasilkan zeolit MFI yang melapisi silika alumina. Grafik XRD yang dihasilkan dari silika alumina sebelum dan sesudah dilapisi dengan zeolit dapat dilihat pada Gambar 5 . 


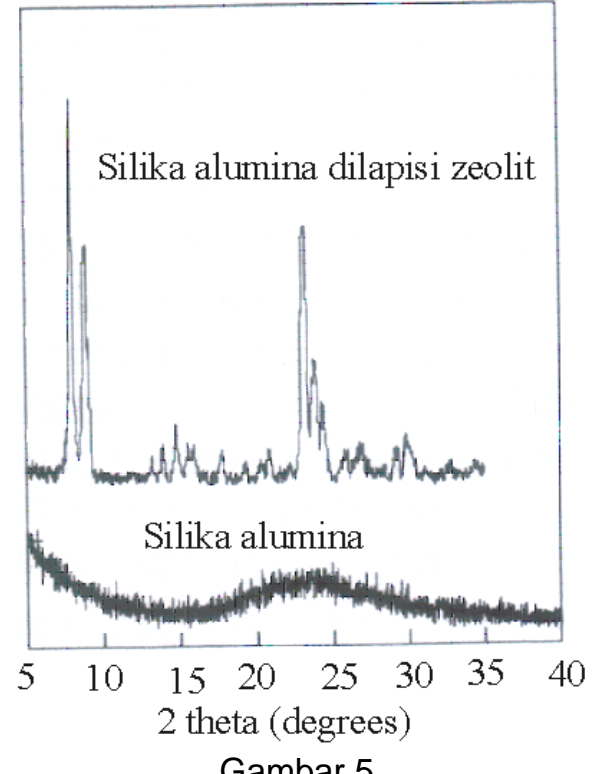

Gambar 5.

Grafik XRD partikel silika alumina sebelum dan sesudah dilapisi dengan membran zeolit.

Pada Gambar 5 tersebut dapat diketahui adanya grafik XRD yang sesuai dengan struktur kristal MFI pada permukaan partikel silika alumina. Tampak berbeda sekali karakteristik yang ditunjukkan pada grafik XRD tersebut bila dibandingkan dengan silika alumina sebelum dilapisi dengan zeolit.

Hasil pengamatan dengan SEM pada permukaan membran reaktor dapat dilihat pada Gambar 6.

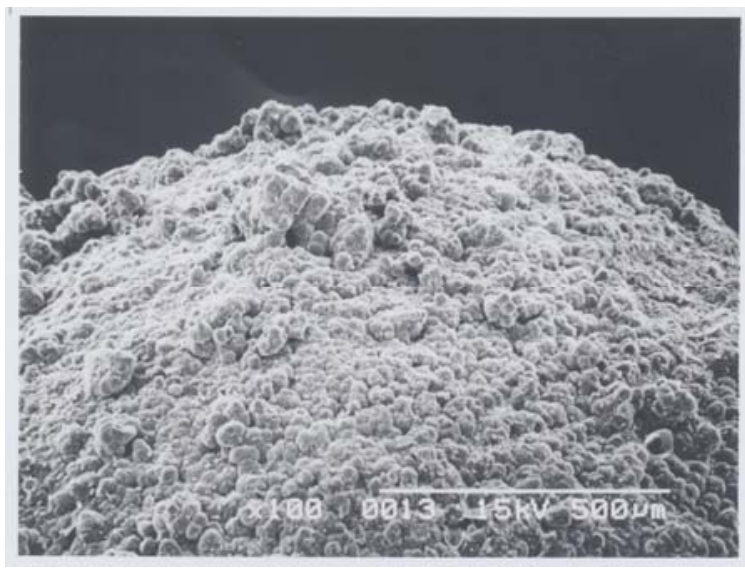

Gambar 6.

Foto SEM permukaan silika alumina yang telah dilapisi zeolit

Hasil analisis adsorpsi-desorpsi isothermal menggunakan nitrogen dapat dilihat pada Gambar 7.

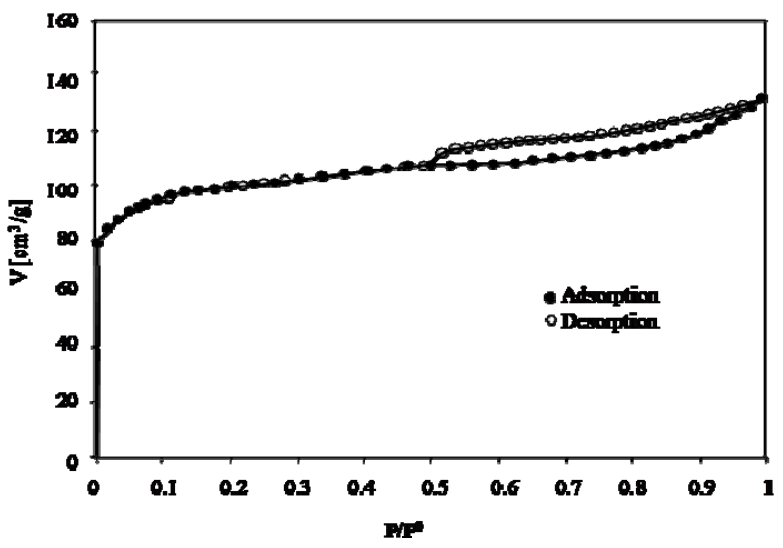

Gambar 7.

Adsorpsi-desorpsi nitrogen pada zeolit MFI

Berdasarkan Gambar 7 jelas terlihat adanya struktur mikroporus pada zeolit $\mathrm{MFI}^{6-7}$, yaitu ditandai dengan kenaikan grafik yang tinggi pada daerah tekanan uap relative $\left(P / P^{0}\right)$ kurang dari 0,1. Pada bagian mesoporous tampak adanya hysteresis, kemungkinan disebabkan oleh perbedaan ukuran pori antara bagian luar dan bagian dalam yang menyerupai gua. Kondisi ini mengakibatkan lambatnya proses desorpsi nitrogen. Adapun profil distribusi ukuran pori membrane MFI yang dihasilkan dapat dilihat pada Gambar 8. Berdasarkan kurva tersebut dapat disimpulkan bahwa membran MFI memiliki ukuran pori yg homogen, rata-rata sekitar $0,55 \mathrm{~nm}$.

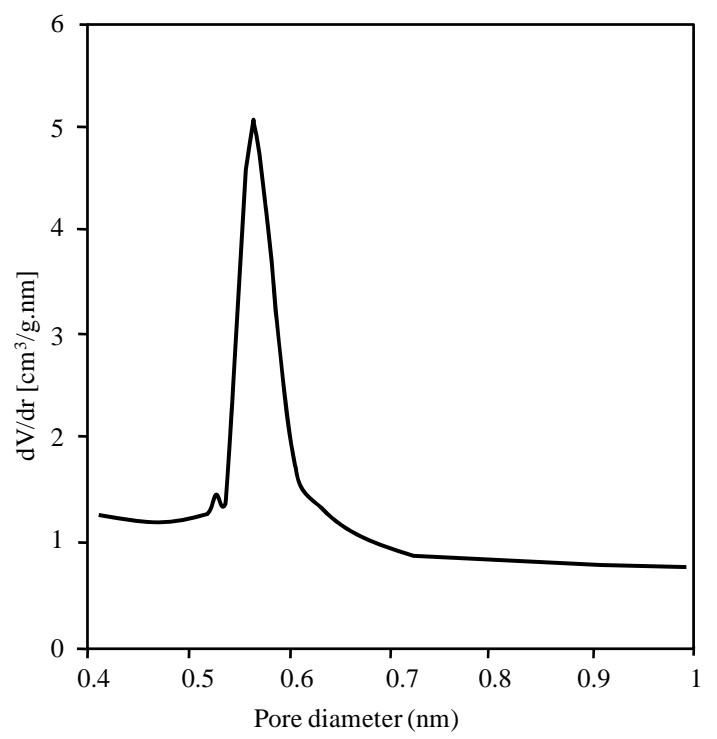

Gambar 8.

Distribusi ukuran pori BJH, zeolit MFI yang dihasilkan

Uji coba pembuatan xylene dari toluena menggunakan membran reaktor tersebut hasilnya dapat dilihat pada tabel 1. 
Tabel 1.

Uji coba pembuatan xylene dari toluene menggunakan silika alumina dan membran reaktor

\begin{tabular}{lllllll}
\hline No. & Sampel Katalis & $\begin{array}{l}\text { Temperatur } \\
\text { proses }(\mathrm{K})\end{array}$ & $\begin{array}{l}\text { Rendemen } \\
\text { Xylene (\%) }\end{array}$ & $\begin{array}{l}\text { Fraksi xylene (\%) } \\
\mathrm{p}\end{array}$ & $\mathrm{m}$ \\
\hline 1. & Silika alumina & 673 & 1,5 & 23 & 52 & 25 \\
2. & Zeolit / silika alumina & 673 & 0,08 & 100 & 0 & 0 \\
& & 773 & 0,4 & 91 & 6 & 3 \\
3. & Zeolit & 673 & 0 & - & - & - \\
\hline
\end{tabular}

Berdasarkan hasil pembuatan xylene dari toluene seperti yang terlihat pada Tabel 1 dapat diketahui bahwa penggunaan katalis silika alumina cukup efektif untuk menghasilkan xylene dengan rendemen yang cukup tinggi, tetapi komposisi para, meta dan orto -xylene nya hampir sama. Sedangkan penggunaan zeolit saja tidak dapat menghasilkan reaksi pembentukan xylene. Dengan membran reaktor zeolit MFI yang dibuat pada katalis silika alumina dapat memisahkan para-xylene dengan sangat selektif terhadap meta- dan orto-xylene. Proses reaksi yang dilakukan pada temperatur $673 \mathrm{~K}$ menunjukkan proses pemisahan terjadi secara sempurna, yaitu mencapai $100 \%$ untuk fraksi p-xylene. Hasil analisis struktur membran setelah panas reaksi pada temperatur $673 \mathrm{~K}$ mengindikasikan stabilitas yang sangat baik, tidak terjadi perubahan.

\section{SIMPULAN}

Suatu membran reaktor dapat dibuat menggunakan zeolit MFI pada katalis silika alumina yang memiliki selektifitas sangat baik terhadap isomer-isomer xylene yaitu ( $p$-xylene) atau dapat dikatakan memiliki para selektifitas. Pada proses yang dilakukan pada temperatur $673 \mathrm{~K}$ terjadi proses pemisahan secara sempurna. Membran zeolit yang dihasilkan dari penelitian memiliki stabilitas yang sangat baik terhadap temperatur tinggi. Distribusi ukuran pori membran yang sempit (homogen), rata-rata sekitar $0,55 \mathrm{~nm}$.

\section{UCAPAN TERIMA KASIH}

Terima kasih kami sampaikan kepada BTMP-BPPT dan IIUM (International Islamic University Malaysia) atas dukungan dan bantuan penggunaan laboratorium untuk penelitian ini.

\section{DAFTAR PUSTAKA}

1. Hsieh, Inorganic Membranes for Separation and Reaction, Elsevier, Amsterdam, 1996.

2. Karge, H.G., J. Weithkamp, Molecular Sieves Science and Technology, Volume 1, Springer, Berlin, 1998.

3. Thomas, J., and Thorpe, M.F., Access in Nanoporous Materials, Plennum Press, New York, 1995.

4. Yeung K.L., Wong L., Sun W., dkk. Patent Number(s): $\quad$ WO2007095859-A1; US2007280878-A1; CN101389374-A. (2007).

5. Haile, T., Nakhla, H., A Novel Zeolite Coating for Protection of Concrete Sewers from Biological Sulfuric Acid Attack, Geomicrobiologi Journal 25 (2008) 322-331

6. Pina, M.P., Mallada, R., Arruebo, M., Urbiztondo, M., Navascués, N., de la Iglesia, O., J. Santamaria, Microporous and Mesoporous Materials 144 (2011) 19-27.

7. Nishiyama, N., L. Gora, V. Teplyakov, F. Kapteijn, J.A. Moulijn, Evaluation of reproducible high flux silicalite-1 membranes : gas permeation and separation characterization, Separation and Purification Technology, Elsevier, 2001. 